Article

\title{
The Application of Functionalized Pillared Porous Phosphate Heterostructures for the Removal of Textile Dyes from Wastewater
}

\author{
José Jiménez-Jiménez ${ }^{1}$, Manuel Algarra ${ }^{1}$ (D), Vanessa Guimarães ${ }^{2}$, Iuliu Bobos ${ }^{2}$ \\ and Enrique Rodríguez-Castellón ${ }^{1, *}$ \\ 1 Departamento de Química Inorgánica, Facultad de Ciencias, Universidad de Málaga, Campus de Teatinos \\ s/n, 29071 Málaga, Spain; jjimenez@uma.es (J.J.-J.); malgarra67@gmail.com (M.A.) \\ 2 Instituto de Ciências da Terra, Porto, DGAOT, Faculdade de Ciências, Universidade do Porto, \\ Rua do Campo Alegre 687, 4169-007 Porto, Portugal; guimavs@gmail.com (V.G.); ibobos@fc.up.pt (I.B.) \\ * Correspondence: castellon@uma.es; Tel.: +34-952-131-873
}

Received: 26 July 2017; Accepted: 13 September 2017; Published: 21 September 2017

\begin{abstract}
A synthesized functionalized pillared porous phosphate heterostructure (PPH), surface functionalized phenyl group, has been used to remove the dye Acid Blue 113 from wastewater. X-ray photoemission spectroscopy XPS and X-ray diffraction (XRD) were used to study its structure. The specific surface area of this was $498 \mathrm{~m}^{2} / \mathrm{g}$. The adsorption capacities of PPH and phenyl surface functionalized $(\Phi-\mathrm{PPH})$ were 0.0400 and $0.0967 \mathrm{mmol} / \mathrm{g}$, respectively, with a dye concentration of $10^{-5} \mathrm{M}$ when well fitted with SIPS and Langmuir isotherms respectively ( $\mathrm{pH} 6.5,25{ }^{\circ} \mathrm{C}$ ). The incorporation of the dye to the adsorbent material was monitored by the $\mathrm{S}$ content of the dye. It is suggested as an alternative for Acid Blue 113 remediation.
\end{abstract}

Keywords: dye remediation; adsorption; azo dye; wastewater; pillared porous phosphate heterostructures; isotherm

\section{Introduction}

Nowadays, among the concerns that must be dealt with on a global level are toxic and carcinogenic environmental pollutants. A large portion of toxic contaminants are dyes, used for dyeing textiles and other industrial purposes. Many physical, chemical and biophysical processes have been studied for their ability to remove environmental pollutants [1]. In particular, the development of new technologies for the easy decolorization or remediation of these types of compounds is of current interest.

Dyes used in the textile industry include a wide range of chemical compounds, based mainly on substituted aromatic structures linked by azo groups [2]; therefore textile dye wastewater is based not only in color removal but also in the degradation, mineralization and total removal. A large variety of techniques has been used including chemical methods such as coagulation [3-5], flocculation [6-8] or precipitation $[9,10]$, and new photocatalytic processes such as the Fenton reaction $[11,12]$ are being implemented and optimized; biological with aerobic and anaerobic microbial degradation [13-15], and the use of pure enzymes $[16,17]$ have been investigated to overcome physical methods such as membrane-filtration processes. Nano-filtration [18-20] reverse osmosis [21], electro-dialysis [22-24] and sorption techniques [25-30] are the most conventional methods due to higher production costs and regeneration difficulties. There is a trend towards developing sustainable water treatment materials and processes [31,32] and consequently, the possibilities of the use of new synthetic material—with low cost and easy availability - are desirable to be evaluated for wastewater management.

Functionalized mesoporous materials are interesting adsorbents in comparison with other commercial DVB or styrene base adsorbents because of their attractive properties, such as a high level 
of heavy metal removal capacity, large surface area, narrow pore size distribution and the specificity of the chelating agents inserted in the network. An emerging group, the synthesized materials are pillared clay structures (PILCs) and similar pillared porous phosphate heterostructures (PPH) [33,34]. These materials can be specifically designed for their use for $\mathrm{Hg}$ (II) and $\mathrm{Ni}$ (II) remediation from the electrochemical industry [35], or catalytic applications [36-40].

We investigate herein, for the first time to the best of our knowledge, the use of PPH modified with functional phenyl groups as a new class of adsorbents for dyes from wastewater. These solids are synthesized from different combinations of silicon precursors and surfactant along with various combinations of condensation processes of alkoxides. The effect of the adsorbate was studied in order to achieve optimal conditions for the adsorption of the azo dye Acid blue (AB113), proving to be an appropriate and cost effective alternative to remove it from wastewater.

\section{Materials and Methods}

\subsection{Synthesis of $\Phi_{x}-P P H$ Adsorbent Materials}

The synthesis of $\Phi_{\mathrm{x}}$-PPH materials was carried out as described elsewhere [35] by co-condensation of phenyl-triethoxysilane (PTES) with tetraethylorthosilicate (TEOS) in the interlayer region of zirconium phosphate. Thus, cetyltrimethylammonium (CTMA)-expanded zirconium phosphate (CTMAZrP) was prepared from a solution of CTMA-Br in 1-propanol, $\mathrm{H}_{3} \mathrm{PO}_{4}(85 \%)$ and zirconium(IV) propoxide (70\%) according to previously reported procedures [33]. The CTMAZrP obtained was suspended in water $(10 \mathrm{~g} / \mathrm{L})$ and a solution of hexadecylamine in 1-propano $(0.145 \mathrm{M})$ was added as a co-surfactant. Increasing the surfactant content in the interlayer region improves the hydrolysis and condensation of the mixture of different alkoxides. After one day of stirring, a solution of TEOS $(50 \%, v / v$ in 1-propanol) and the corresponding PTES-with TEOS/PTES molar ratios of 5, 25 and 50-were added, and in each case the resulting suspension was stirred at room temperature for three days. The obtained solids were centrifuged, washed with ethanol and dried at $60{ }^{\circ} \mathrm{C}$ in air. After this stage, silica galleries are formed between the layers of zirconium phosphate and the surfactant molecules are located inside these galleries. To release this space, it has proceeded to the removal of the surfactant by cation exchange with a solution of $\mathrm{HCl}$ in ethanol, because the calcination process is not a suitable procedure due to the removal of the phenyl functionalized silica walls in the galleries. After various tests, both the extractor solution concentration and the number of extractions were optimzed, yielding greater efficiency in the extraction process (three times) at a concentration of HCl:ethanol (1:10; v:v). Three materials with different TEOS/PTES molar ratio added $(\times)$ are denoted as $\Phi_{\mathrm{x}}-\mathrm{PPH}$. All reagents used were purchased from Sigma-Aldrich (Barcelona, Spain).

\subsection{Adsorption Experiments AB113 in Solution Data Analysis}

Batch adsorption experiments were performed at room temperature adding $50 \mathrm{mg}$ of $\Phi_{\mathrm{x}}-\mathrm{PPH}$ at different volumes (a range of volumes was used) of $10^{-5} \mathrm{M}$ of AB113. After one day, the solid was removed by centrifugation and the solution was analysed by UV-Vis spectroscopy. The Langmuir model assumes that the sorption sites are identical and energetically equivalent due to its homogeneous structure [41,42]. The equilibrium is obtained when the monolayer formation on the sorbent occurs. The Langmuir isotherm is described according to the following equation (Equation (1)):

$$
q_{e}=\frac{q_{m} K_{L} C_{e}}{1+K_{L} C_{e}}
$$

where, $q_{e}(\mathrm{~mol} / \mathrm{kg})$ and $C_{e}(\mathrm{~mol} / \mathrm{L})$ are the equilibrium concentrations of $\mathrm{AB} 113$ in the solid and the liquid phase, respectively, $q_{m}(\mathrm{mmol} / \mathrm{g})$ is the maximum sorption capacity and $K_{L}(\mathrm{~L} / \mathrm{kg})$ is the Langmuir constant related to the energy of adsorption. $q_{e}$ is obtained according to Equation (2):

$$
q_{e}=\left(C_{i}-C_{f}\right) \frac{V}{m}
$$


where, $C_{i}$ and $C_{f}$ are the concentrations of AB113 at the beginning and the end of the adsorption process, $V$ is the solution volume used during batch experiments (a range of volumes was used) and $\mathrm{m}$ is the mass of $\Phi_{5}-\mathrm{PPH}$ used.

The Freundlich model was used to describe the adsorption of contaminants on heterogeneous surfaces consisting of sites with different exponential distribution and energies [41,42]. The equation of the Freundlich sorption isotherm is expressed by Equation (3):

$$
q_{e}=K_{F} C_{e}^{n}
$$

where, $K_{F}$ and $n$ are the Freundlich adsorption isotherm constants, being indicative of the adsorption extension and the degree of the surface heterogeneity. The SIPS isotherm combines both Freundlich and Langmuir isotherms, which at low adsorbate concentration behaves as the Freundlich isotherm [41] and at high concentration it predicts a monolayer adsorption capacity characteristic to the Langmuir model [41]. The mathematical representation of this model is given by Equation (4):

$$
q_{e}=\frac{q_{m}\left(K_{s} C_{e}\right)^{n}}{1+\left(K_{s} C_{e}\right)^{n}}
$$

where, $q_{m}(\mathrm{~mol} / \mathrm{kg})$ is the maximum adsorption capacity, which can also be expressed as $\mathrm{Nt}$, a measure of the total number of binding sites available per $g$ of sorbent, $K_{S}$ is the affinity constant for adsorption $(\mathrm{L} / \mathrm{kg})$ and $n$ is the Freundlich parameter that takes into account the system heterogeneity. The SIPS isotherm is reduced to the Langmuir form for $n=1$ and a homogeneous surface is considered. The greater the difference from this value, the greater the solid surface heterogeneity.

\subsection{Characterization Methods}

UV-Vis measurements were carried out with a Shimadzu UV-1800 spectrophotometer (Shimadzu Corporation, Kyoto, Japan). Powder diffraction patterns were collected on an X'Pert Pro MPD automated diffractometer (PANalytical, Almelo, The Netherlands) equipped with a $\mathrm{Ge}(111)$ primary monochromator (strictly monochromatic $\mathrm{Cu}-\mathrm{K}_{\alpha}$ radiation) and an $X^{\prime}$ Celerator detector (PANalytical, Almelo, The Netherlands). Textural parameters were obtained from $\mathrm{N}_{2}$ adsorption-desorption isotherms with a Micromeritics ASAP 2020 (Micromeritics Ltd., Bedfordshire, UK). The specific surface area and pore volume of the $\Phi_{\mathrm{x}}-\mathrm{PPH}$ were determined by the adsorption-desorption of $\mathrm{N}_{2}$ at $-196{ }^{\circ} \mathrm{C}$. Before analysis, the $\Phi_{\mathrm{x}}-\mathrm{PPH}$ samples were degassed at $150^{\circ} \mathrm{C}$ up to $10^{-4}$ Torr. Pore volume and an average pore diameter were determined by the Barrett, Joyner, Halenda model. X-ray photoelectron spectra (XPS) were obtained using a Physical Electronics PHI 5700 spectrometer with a non-monochromatic $\mathrm{Mg} \mathrm{K} \alpha$ radiation $(300 \mathrm{~W}, 15 \mathrm{kV}, h v=1256.3 \mathrm{eV})$ as the excitation source. Spectra were recorded at $45^{\circ}$ take-off angles by a concentric hemispherical analyser (Physical Electronics, Inc., Chanhassen, MN, USA) operating in the constant pass energy mode at $25.9 \mathrm{eV}$, using a $720 \mu \mathrm{m}$ diameter analysis area. Under these conditions the $\mathrm{Au} 4 f_{7 / 2}$ line was recorded with $1.16 \mathrm{eV}$ FWHM at a binding energy of $84.0 \mathrm{eV}$. The spectrometer energy scale was calibrated using $\mathrm{Cu} 2 p_{3 / 2}, \mathrm{Ag} 3 d_{5 / 2}$ and $\mathrm{Au} 4 f_{7 / 2}$ photoelectron lines at 932.7, 368.3 and $84.0 \mathrm{eV}$, respectively. Charge referencing was done against adventitious carbon ( $\mathrm{C} 1 \mathrm{~s} 284.8 \mathrm{eV}$ ). The $\mathrm{C} 1 \mathrm{~s}$ signal of some samples was also studied with an $\mathrm{Al} \mathrm{K}_{\alpha}$ radiation due to the presence of sodium to avoid the overlapping of the Na KLL Auger signal at $290.3 \mathrm{eV}$. Solid surfaces were mounted on a sample holder without adhesive tape and kept overnight in a high vacuum in the preparation chamber before they were transferred to the analysis chamber of the spectrometer. Each region was scanned with several sweeps until a good signal-to-noise ratio was observed. The pressure in the analysis chamber was maintained lower than $10^{-9}$ Torr. A Shirley-type background was subtracted from the signals. Recorded spectra were always fitted using Gauss-Lorentz curves in order to determinate more accurately the binding energy of the different element core levels. The accuracy of binding energy (BE) values was within $\pm 0.1 \mathrm{eV}$. 


\section{Results and Discussion}

\subsection{Adsorbent Characterization}

Elemental analysis does not provide enough information to determine the presence of phenyl groups. The residual surfactant and the alcohol adsorbed used in the extraction procedure can interfere in the carbon content $(\% \mathrm{C})$. Therefore, the phenyl incorporation cannot be determined by $\mathrm{CHN}$ elemental analysis. However, the increasing \%C when phenyl groups are grafted was observed. Thus, for the extracted materials in which the amount of surfactant present is residual, the observed differences in the \%C are remarkable, being this C \% higher for material $\Phi_{5}-\mathrm{PPH}(9.04 \%)$ and reduced for $\Phi_{50}-\mathrm{PPH}(2.62 \%)$, as displayed in Table 1.

Table 1. Chemical composition of $\Phi$-PPH material.

\begin{tabular}{ccccc}
\hline Material & $\mathbf{\% C}$ & $\mathbf{\% N}$ & $\mathbf{\%} \mathbf{C}^{*}$ & $\mathbf{\% N} \mathbf{N}^{*}$ \\
\hline$\Phi_{5}-\mathrm{PPH}$ & 9.04 & 0.147 & 19.53 & 1.30 \\
$\Phi_{25}-\mathrm{PPH}$ & 3.81 & 0.217 & 18.91 & 1.27 \\
$\Phi_{50}-\mathrm{PPH}$ & 2.62 & 0.222 & 18.53 & 1.28 \\
\hline \multicolumn{5}{c}{}
\end{tabular}

The concentration of phenyl groups in the synthesized material was determined by UV-VIS spectroscopy at $\lambda=210 \mathrm{~nm}$ in hexane. As seen in the UV-VIS spectra (Figure 1), the absorption due to the phenyl groups decreases with the TEOS/ $\Phi$ molar ratio. A calibration curve was performed by hydrolysis of different amounts of phenyl triethoxysilane and the amount of phenyl groups incorporated in each material was determined (Table 2). As expected, the highest observed incorporation of phenyl groups occurred with sample $\Phi_{5}-\mathrm{PPH}$, although the found value $(0.047 \mathrm{mmol} / \mathrm{g})$ was below the theoretical one if all the phenyl groups added were incorporated to the structure. This fact may be due to steric effects and to the non-polar character of phenyl groups which prevents their presence in large amounts in the interlayer space, giving a low incorporation when the silica galleries are formed upon hydrolysis and condensation of PTES, together with the TEOS.

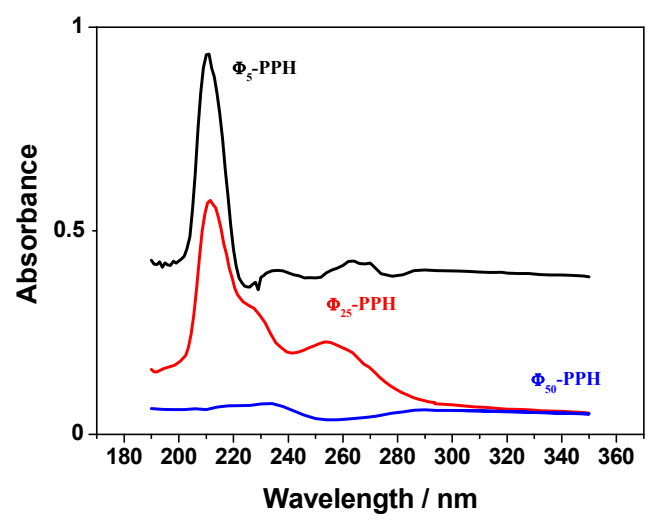

Figure 1. UV-Vis spectra of $\Phi_{5}-\mathrm{PPH}, \Phi_{25}-\mathrm{PPH}$ and $\Phi_{50}-\mathrm{PPH}$ at $210 \mathrm{~nm}$ in hexane.

Table 2. Characteristics of the different materials synthesized.

\begin{tabular}{|c|c|c|c|c|c|c|c|c|c|c|}
\hline Material & $\mathrm{mmol} \Phi / \mathrm{g}$ & $\mathrm{mmol} \mathrm{P/g}$ & $\Phi / P(\operatorname{Exp})$ & $\Phi / P(\operatorname{Exp})$ & $\begin{array}{c}\mathrm{S}_{\mathrm{BET}} \\
\left(\mathrm{m}^{2} / \mathrm{g}\right)\end{array}$ & $\underset{\left(\mathrm{cm}^{3} / \mathrm{g}\right)}{V p}$ & $\mathrm{C}_{\text {BET }}$ & $\begin{array}{c}\mathrm{S}_{\mathrm{ac}} \\
\left(\mathrm{m}^{2} / \mathrm{g}\right)\end{array}$ & $\begin{array}{c}\Sigma V_{p} \\
\left(\mathrm{~cm}^{3} / \mathrm{g}\right)\end{array}$ & $\mathrm{Dp}(\AA ̊)$ \\
\hline$\Phi_{5}-\mathrm{PPH}$ & 0.047 & 1.73 & 0.027 & 0.6 & 498 & 0.516 & 133 & 482 & 0.472 & 39.13 \\
\hline$\Phi_{25}-\mathrm{PPH}$ & 0.042 & 1.86 & 0.023 & 0.12 & 545 & 0.596 & 123 & 540 & 0.565 & 41.87 \\
\hline$\Phi_{50}-\mathrm{PPH}$ & 0.003 & 1.78 & 0.002 & 0.06 & 571 & 0.657 & 133 & 546 & 0.609 & 44.59 \\
\hline
\end{tabular}

* Previous tensioactive extraction and $\bullet$ Determinated by the Cranston e Inkley method. 
This also justifies the found number of functional groups incorporated into the material $\Phi_{25}-\mathrm{PPH}$ that is only slightly lower than that found for $\Phi_{5}-\mathrm{PPH}$, despite the fact that the amount of functionalized alkoxide added to the latter was five times the added amount in the case of $\Phi_{25}-\mathrm{PPH}$. However, in spite of the increase in the number of phenyl groups incorporated, the final absorbance remained constant. Finally, as expected, in the case of material $\Phi_{50}-\mathrm{PPH}$, the incorporation of phenyl groups in this material is very low.

After removing the surfactant used as a template, the inner silica galleries are free and a porous material is obtained. For hybrid $\Phi_{\times}-\mathrm{PPH}$, the surface phenyl groups are directed to the inner porous material. This is true if the inorganic framework is preserved after surfactant removal.

This fact can be determined by studying the corresponding XRD diffractograms. The results show a single broad signal at a low angle corresponding to the $\mathrm{d}_{001}$ reflection, showing the separation of the layers of zirconium phosphate (Figure 2A). This confirms the presence of silica galleries in the interlayer region of zirconium phosphate, which keep these layers separate when the surfactant has been removed.
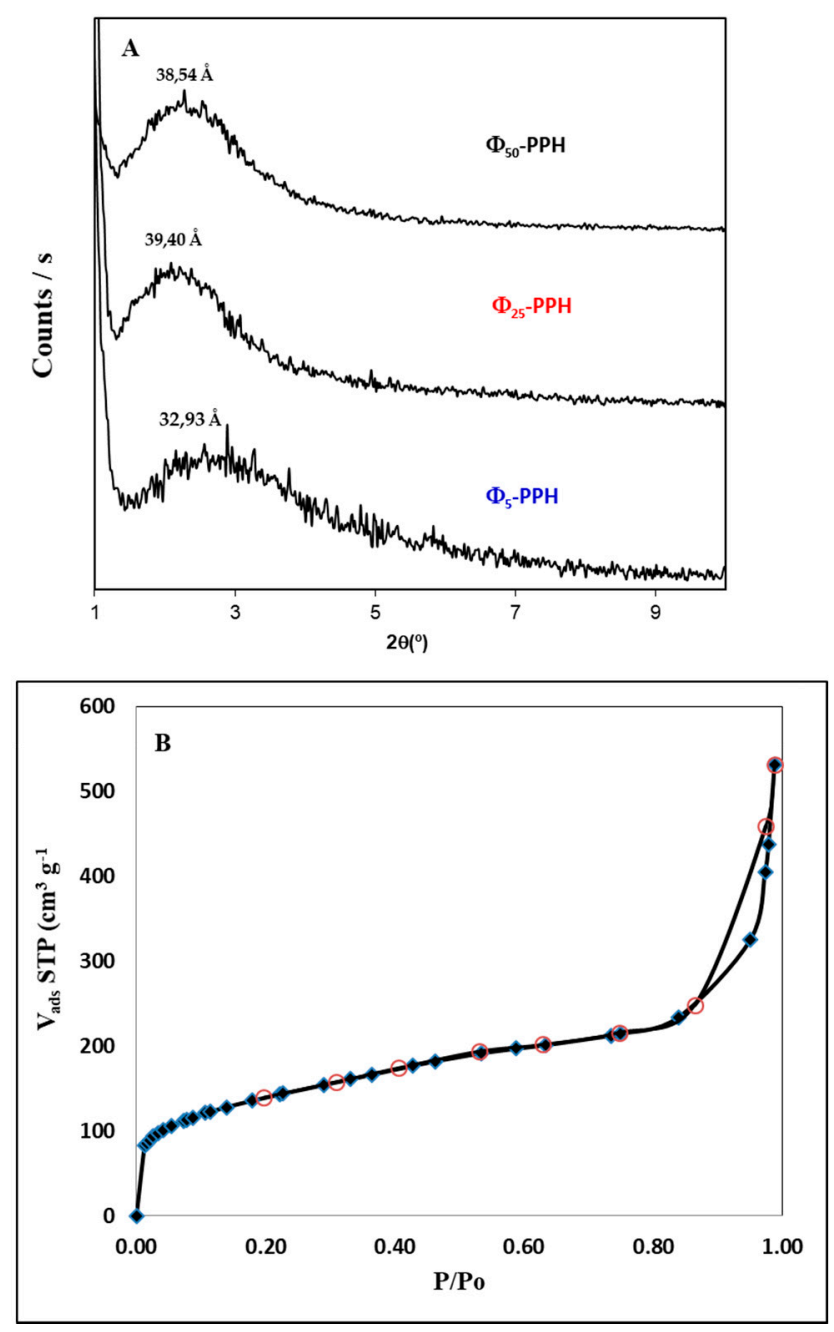

Figure 2. (A) XRD pattern of $\Phi_{5}-\mathrm{PPH}, \Phi_{25}-\mathrm{PPH}$ and $\Phi_{50}-\mathrm{PPH} ;(\mathbf{B}) \mathrm{N}_{2}$ adsorption-desorption isotherms at $77 \mathrm{~K}$ of $\Phi_{5}-\mathrm{PPH}$.

In $\Phi_{5}-\mathrm{PPH}$, the diffraction peak appears at a slightly lower angle so that the basal spacing is $32.9 \AA$, the intensity is weak and the definition of the peak poor. This indicates that the presence of phenyl groups hinders the arrangement of the internal phase material. This low crystallinity can be justified by the steric hindrance of the phenyl groups, due to their non-polar character, since the 
surfactant micelles which act as structural elements of the silica galleries present a polar end placed in this environment which hinders the correct formation of the inorganic structure, mainly for the precursors which contain the phenyl group. This fact is reflected, as discussed in the previous section, in the incorporation of organic groups where the amount of phenyl groups is lower than the other functionalized PPH studied [35].

The evaluation of the typical textural parameters such as surface area and pore size distribution will confirm the formation of silica in the galleries of the interlayer region. Textural parameters obtained from the corresponding Nitrogen adsorption-desorption isotherms of $\mathrm{N}_{2}$ at $-196{ }^{\circ} \mathrm{C}$ correspond to type IV (IUPAC) [36,37], characteristic of mesoporous materials (Figure 2B, Table 2). The surface area values $\left(\mathrm{S}_{\mathrm{BET}}\right.$ ) obtained are quite high (above $500 \mathrm{~m}^{2} / \mathrm{g}$ ), indicating a large accessible surface within the material due to the presence of silica galleries in the interlayer region being lower than the pure heterostructures $\left(620 \mathrm{~m}^{2} / \mathrm{g}\right)$ [33], showing that the incorporation of phenyl groups decreases the surface area of the material. Regarding the volume of pores $\left(\mathrm{V}_{\mathrm{p}}\right)$, these materials have very high values, even more than the pure silica heterostructures $\left(0.543 \mathrm{~cm}^{3} / \mathrm{g}\right)$. This may be due to the presence of larger pore diameters as shown in the distribution of pores.

The surface chemical composition of the adsorbent $\Phi_{5}-\mathrm{PPH}$ before and after contact with $\mathrm{AB} 113$ (sample $\Phi_{5}-\mathrm{PPH}+\mathrm{AB113}$ ) is shown in Table 3. Upon contact with the dye, the percentages of $\mathrm{C}$ and $\mathrm{N}$ increase and $\mathrm{S}$ are now detected. However, $\mathrm{Na}$ was not detected indicating that the dye anion was taken up. The empiric formula of the dye anion is $\mathrm{C}_{32} \mathrm{H}_{21} \mathrm{~N}_{5} \mathrm{O}_{6} \mathrm{~S}_{2}$ and the theoretical N/S atomic ratio is 2.5. The observed N/S atomic ratio after incorporation of the dye is 2.6 , a value very near the theoretical one indicating the incorporation of the dye. Sulfur is the only element of the dye that is not present in the adsorbent $\Phi_{5}-\mathrm{PPH}$ and the $\mathrm{S} 2 p$ core level spectrum for sample $\Phi_{5}-\mathrm{PPH}+\mathrm{AB} 113$ shows a S $2 p_{3 / 2}$ contribution at $168.2 \mathrm{eV}$ assigned to the presence of $\mathrm{S}(\mathrm{VI})$ as the sulfonic group of the dye [43].

Table 3. Atomic concentration (\%) of samples $\Phi_{5}-\mathrm{PPH}$ and $\Phi_{5}-\mathrm{PPH}+\mathrm{AB} 113$ determined by XPS.

\begin{tabular}{cccccccc}
\hline Sample & $\mathbf{C}$ & $\mathbf{N}$ & $\mathbf{O}$ & $\mathbf{S i}$ & $\mathbf{P}$ & $\mathbf{Z r}$ & $\mathbf{S}$ \\
\hline$\Phi_{5}-\mathrm{PPH}$ & 24.50 & 0.50 & 50.07 & 19.55 & 3.52 & 1.86 & - \\
$\Phi_{5}-\mathrm{PPH}+\mathrm{AB} 113$ & 29.56 & 0.94 & 46.00 & 18.42 & 2.19 & 1.69 & 0.36 \\
\hline
\end{tabular}

\subsection{Adsorption Isotherms}

From the results obtained after chemical, structural and textural characterization, $\Phi_{5}-\mathrm{PPH}$ material was selected as adsorbent for AB113, given that it presents the highest phenyl group surface density (Table 1). Also, to evaluate the effect of the phenyl group on the AB113 adsorption, the pristine PPH material was used as a reference. AB113 adsorption isotherms were investigated in triplicate at $25^{\circ} \mathrm{C}$ and $\mathrm{pH} 6.5$.

Figure 3 shows the fitting of the experimental data to the adsorption isotherms for $\mathrm{PPH}$ and $\Phi_{5}-\mathrm{PPH}$ respectively. In the case of pristine $\mathrm{PPH}$, the isotherm was fitted to the SIPS isotherm with a saturated adsorption capacity of $0.04 \mathrm{mmol} / \mathrm{g}$ (Figure $3 \mathrm{~A}$ ). The adsorption data from $\Phi_{5}-\mathrm{PPH}$ were fitted to a Langmuir isotherm model, showing a saturated adsorption capacity $\left(\mathrm{Q}_{\mathrm{o}}\right)$ of $0.0967 \mathrm{mmol} / \mathrm{g}$ and a Langmuir constant $\left(\mathrm{K}_{\mathrm{L}}\right)$ of $613 \mathrm{~L} / \mathrm{Kg}$ (Figure 3B). Other model fittings are shown as supplementary information as Figure $\mathrm{S} 1$.

The adsorption effectiveness was also evaluated. The retention effectiveness was close to $100 \%$ for $\Phi_{5}-\mathrm{PPH}$ material, when the adsorption capacity was lower than $0.040 \mathrm{mmol} / \mathrm{g}$. From this point it decreases while increasing the amount of AB113 in the solution. For the pure PPH material, the highest retention percentage reached was $55 \%$ for the first fit, decreasing in the next points. In the literature, AB113 adsorption on mesoporous activated carbon is reported [44], where the observed adsorption capacities are in the order obtained for $\Phi_{5}-\mathrm{PPH}$. In this case the adsorption capacities for an activated carbon obtained from a rubber tyre and for a commercial activated carbon obtained from the Langmuir isotherm $\left(Q_{0}\right)$, were 0.014 and $0.011 \mathrm{mmol} / \mathrm{g}$, respectively, although for both activated carbons the 
specific surface areas are higher than that observed for $\Phi_{5}-\mathrm{PPH}$ with values of 562 and $1168 \mathrm{~m}^{2} / \mathrm{g}$. Another adsorbent based in red mud obtained a $Q_{o}=0.112 \mathrm{mmol} / \mathrm{g}$ [45], demonstrating the feasibility of the proposed system to be applied.

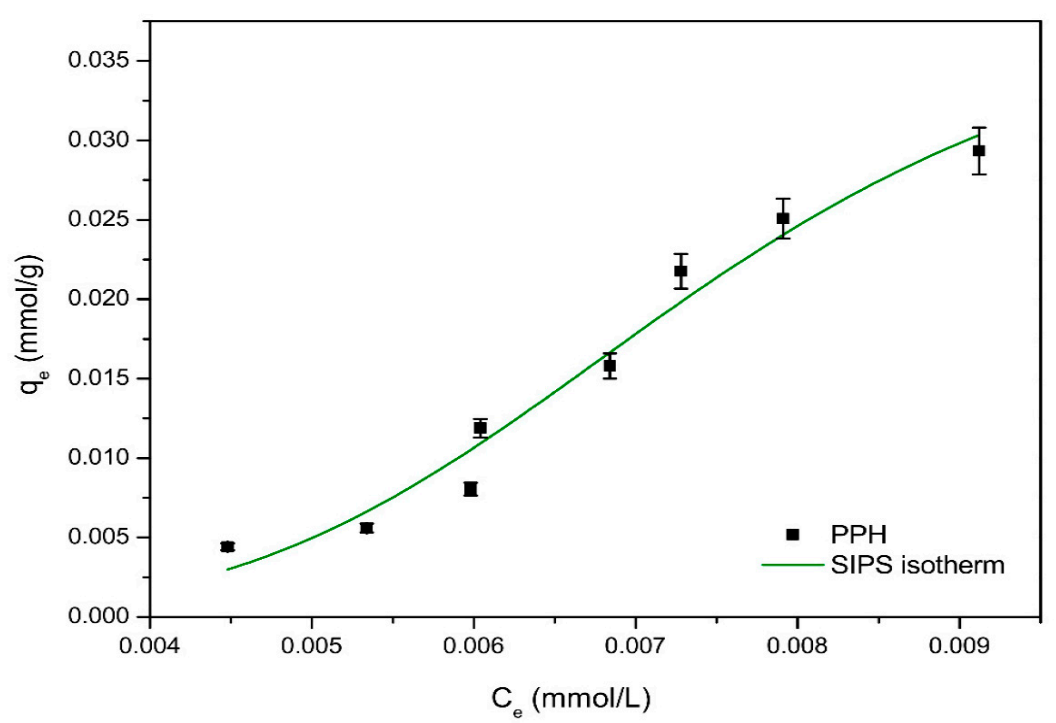

(A)

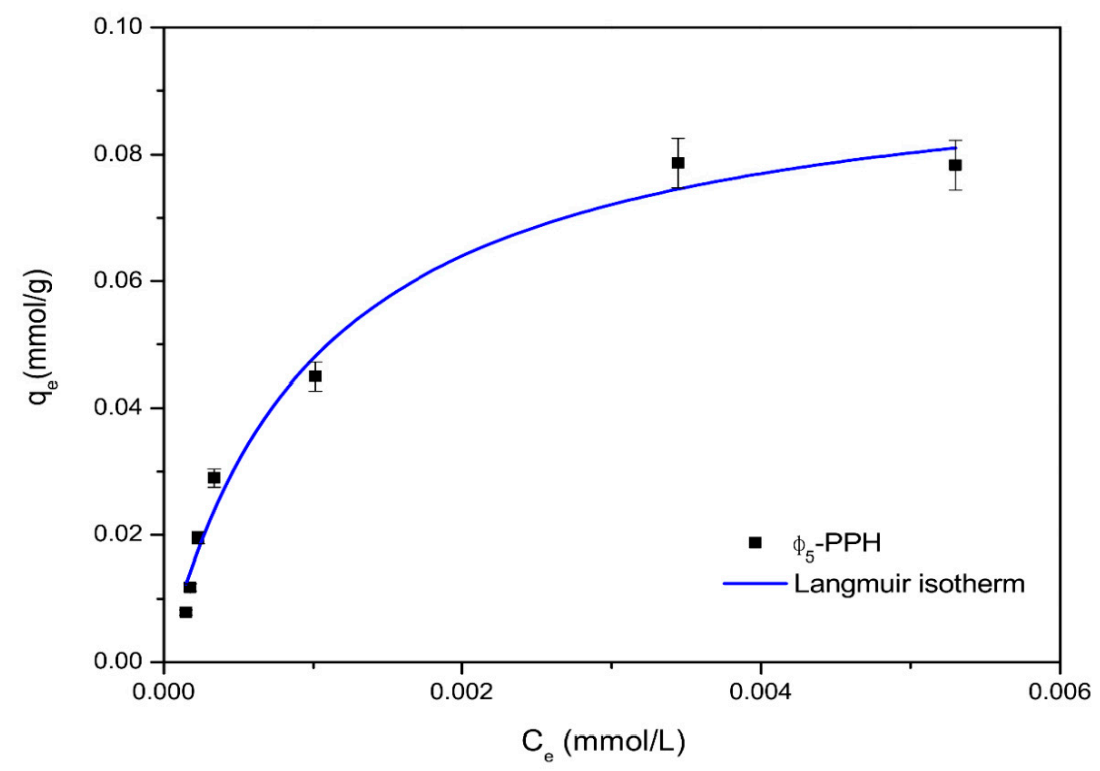

(B)

Figure 3. AB113 adsorption isotherms in (A) PPH and (B) $\Phi_{5}-\mathrm{PPH}$ and in relation to mmol AB113 for g of sorbent.

The difference in the adsorption capacities of PPH and $\Phi_{5}-\mathrm{PPH}$ can be explained by the difference in the intermolecular forces between the different surface groups and the dye monomer. In the case of $\mathrm{PPH}$, the main forces involved are strong hydrogen bonding with the $\mathrm{AB} 113$ ( $\mathrm{Si}-\mathrm{OH}$ and $\mathrm{P}-\mathrm{OH}$ ) and the presence of aromatic rings on the surface of phenyl-functionalized $\Phi_{5}-\mathrm{PPH}$ which offer a superior degree of delocalization due to the $\pi-\pi$ stacking of the phenyl surface groups of the adsorbent (Figure 4). The different mechanisms of adsorption are also indicated by the fit of sorption data to two distinct isothermal models. The better fit of the $\Phi_{5}-\mathrm{PPH}$ sorption data to the Langmuir isotherm reveals that the sorption sites are identical and energetically homogeneous, suggesting that the coordination between $\mathrm{AB} 113$ and the aromatic rings of $\Phi_{5}-\mathrm{PPH}$ is the main mechanism of adsorption involved. 
However, the better fit of PPH sorption data to the SIPS isotherm indicates that there is more than one type of site involved in this process, each characterized by distinct energies and distinct affinities to adsorb. In this case, it is particularly related to the adsorption on the $\mathrm{Si}-\mathrm{OH}$ and $\mathrm{P}-\mathrm{OH}$ groups of $\mathrm{PPH}$. To demonstrate the mechanism described, decreasing a specific area in our material does not limit increased dye adsorption.

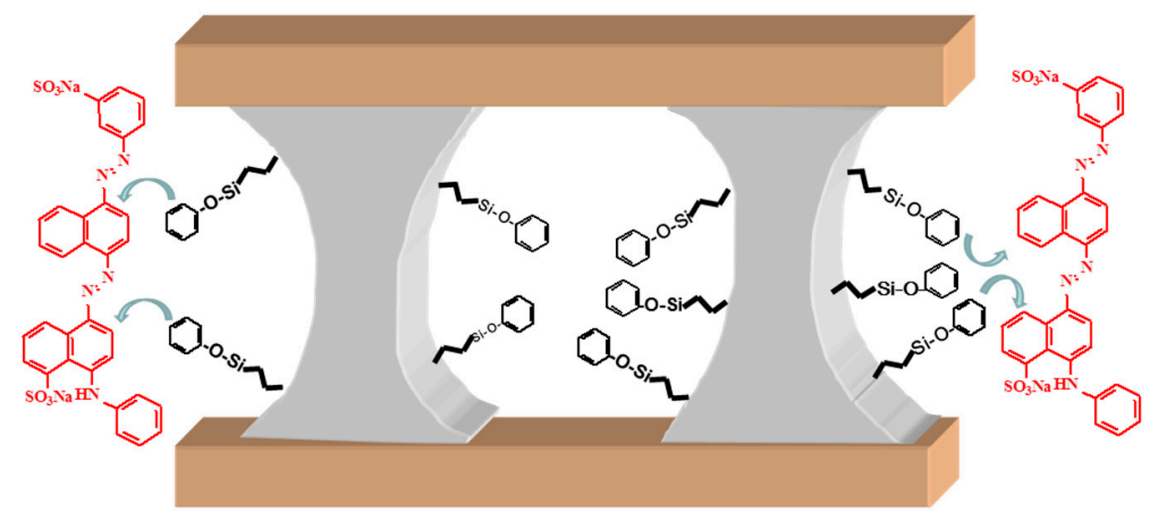

Figure 4. Proposed mechanism of interaction between $\Phi_{5}-\mathrm{PPH}$ and AB113.

The various applications of phenyl functionalized adsorbent have been reported in recent literature [46-49]. However, the current work is unique in terms of the use of phenyl-PPH for dye adsorption, which is reported here for the first time.

\subsection{Application in Wastewater}

In accordance with the results previously obtained, $\Phi_{5}-\mathrm{PPH}$ was used as an adsorbent material for treating real wastewater from a local textile stamp factory. Figure 5 shows the absorbance at $270 \mathrm{~nm}$ of water from a rinse step treated with different mass sorbent, where the absorbance at $270 \mathrm{~nm}$ achieves the minimum from a mass/volume ratio of $10 \mathrm{~g} / \mathrm{m}^{3}$, which indicates that this type of hybrid phenyl material can be a promising dye scavenger.

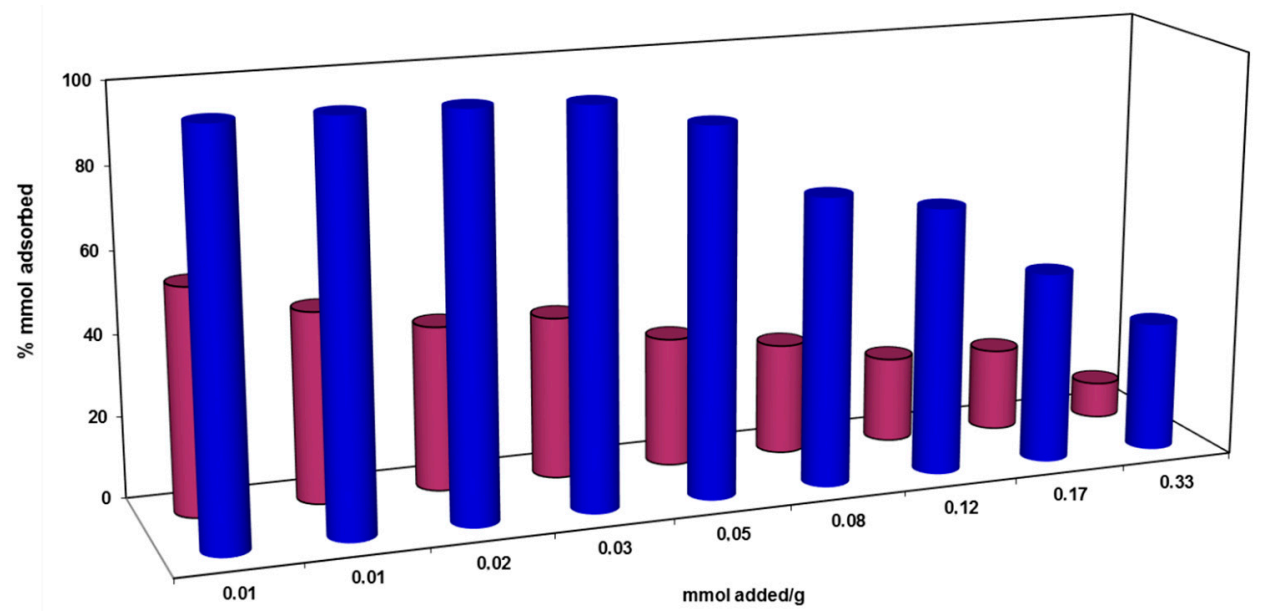

Figure 5. Remediation of an azo dye from industrial textile wastewater by $\Phi_{5}-\mathrm{PPH}$ recorded at $270 \mathrm{~nm}$ (घ) and compared with raw PPH (

\section{Conclusions}

The functionalized porous phosphate heterostructure materials with phenyl functionalized surface proved to be effective adsorbents for the removal of AB113 azo dye from wastewater from the textile 
industry. With a surface area (SBET) of $500 \mathrm{~m}^{2} / \mathrm{g}$, the best known adsorption process is Langmuir, compared to the other tested models such as Freundlich and SIPS, showing saturation $\left(Q_{o}\right)$ of $0.0967 \mathrm{mmol} / \mathrm{g}$. An adsorption mechanism is proposed between the phenyl groups of the $\Phi_{5}-\mathrm{PPH}$ and AB113, based on the affinity between both groups due to $\pi-\pi$ stacking, suggested by the Langmuir model. The results indicate that $\Phi_{5}-\mathrm{PPH}$ is a good alternative to remove the azo dye from industrial wastewater, as shown in the application studied and supported by XPS analysis of the surface of $\Phi_{5}-\mathrm{PPH}$ after the application of the N/S ration.

Supplementary Materials: The following are available online at www.mdpi.com/1996-1944/10/10/1111/s1, Figure S1: Fitting of experimental adsorption of AB113 on $\Phi_{5}-\mathrm{PPH}$.

Acknowledgments: This work was supported by the project MINECO CTQ2015-68951-C3-3-R and FEDER funds. V. Guimarães thanks the PhD scholarship (Ref. SFRH/BD/79969/2011) financed by Fundação para a Ciência e Tecnologia (FCT), Portugal.

Author Contributions: Authors have contributed equally in all the work.

Conflicts of Interest: The authors declare no conflict of interest.

\section{References}

1. Lichtfouse, E.; Schwarzbauer, J.; Robert, D. Environmental Chemistry. Green Chemistry and Pollutants in Ecosystems; Springer: Berlin, Germany, 2005.

2. Hunger, K. (Ed.) Industrial Dyes. Chemistry, Properties, Applications; Wiley-VCH: Weinheim, Germany, 2003.

3. Shi, B.; Li, G.; Wang, D.; Feng, C.; Tang, H. Removal of direct dyes by coagulation: The performance of preformed polymeric aluminum species. J. Hazard. Mater. 2007, 143, 567-574. [CrossRef] [PubMed]

4. Alinsafi, A.; Khemis, M.; Pons, M.N.; Leclerc, J.P.; Yaacoubi, A.; Benhammou, A.; Nejmeddine, A. Electro-coagulation of reactive textile dyes and textile wastewater. Chem. Eng. Process. Process Intensif. 2005, 44, 461-470. [CrossRef]

5. Cañizares, P.; Martínez, F.; Jiménez, C.; Lobato, J.; Rodrígo, M.A. Coagulation and electrocoagulation of wastes polluted with dyes. Environ. Sci. Technol. 2006, 40, 6418-6424. [CrossRef] [PubMed]

6. Zonoozi, M.H.; Moghaddam, M.R.; Arami, M. Coagulation/flocculation of dye-containing solutions using polyaluminium chloride and alum. Water Sci. Technol. 2009, 59, 1343-1351. [CrossRef] [PubMed]

7. Moghaddam, S.S.; Moghaddam, M.R.A.; Arami, M. Coagulation/flocculation process for dye removal using sludge from water treatment plant: Optimization through response surface methodology. J. Hazard. Mater. 2010, 175, 651-657. [CrossRef] [PubMed]

8. Petzold, G.; Schwarz, S.; Mende, M.; Jaeger, W. Dye flocculation using polyampholytes and polyelectrolyte-surfactant nanoparticles. J. Appl. Polym. Sci. 2007, 104, 1342-1349. [CrossRef]

9. Lemlikchi, W.; Sharrock, P.; Mecherri, M.O.; Fiallo, M.; Nzihou, A. Reaction of calcium phosphate with textile dyes for purification of wastewaters. Desalin. Water Treat. 2014, 52, 1669-1673. [CrossRef]

10. Raïs, Z.; El Hassani, L.; Maghnouje, J.; Hadji, M.; Ibnelkhayat, R.; Nejjar, R.; Kherbeche, A.; Chaqroune, A. Dyes' removal from textile wastewater by phosphogypsum using coagulation and precipitation method. Phys. Chem. News 2002, 7, 100-109.

11. Lucas, M.S.; Algarra, M.; Jiménez-Jiménez, J.; Rodríguez-Castellón, E.; Péres, J.A. Catalytic Activity of Porous Phosphate Heterostructures-Fe towards Reactive Black 5 Degradation. Int. J. Photoenergy 2013, 2013, 658231. [CrossRef]

12. Lucas, M.S.; Tavares, P.B.; Péres, J.A.; Farias, J.L.; Rocha, M.; Pereira, C.; Freire, C. Photocatalytic degradation of Reactive Black 5 with $\mathrm{TiO}_{2}$-coated magnetic nanoparticles. Catal. Today 2013, 209, 116-121. [CrossRef]

13. Senan, R.C.; Shaffiqu, T.S.; Roy, J.J; Abaham, T.E. Aerobic Degradation of a Mixture of Azo Dyes in a Packed Bed Reactor Having Bacteria-Coated Laterite Pebbles. Biotechnol. Prog. 2003, 19, 647-651. [CrossRef] [PubMed]

14. De los Cobos-Vasconcelos, D.; Ruiz-Ordaz, N.; Galíndez-Mayer, J.; Galíndez-Mayer, H.; Juàrez-Ramírez, C.; Aarón, L.M. Aerobic biodegradation of a mixture of sulfonated azo dyes by a bacterial consortium immobilized in a two-stage sparged packed-bed biofilm reactor. Eng. Life Sci. 2012, 12, 39-48. [CrossRef] 
15. O’Neill, C.; López, A.; Esteves, S.; Hawkes, F.R.; Hawkes, D.L.; Wilcox, S. Azo-dye degradation in an anaerobic-aerobic treatment system operating on simulated textile effluent. Appl. Microbiol. Biotechnol. 2000, 53, 249-254. [CrossRef] [PubMed]

16. Shah, P.D.; Dave, S.R.; Rao, M.S. Enzymatic degradation of textile dye Reactive Orange 13 by newly isolated bacterial strain Alcaligenes faecalis PMS-1. Int. Biodeterior. Biodegrad. 2012, 69, 41-50. [CrossRef]

17. Shaffiqu, T.S.; Roy, J.J.; Nair, R.A.; Abraham, T.E. Degradation of textile dyes mediated by plant peroxidases. Appl. Biocem. Biotechnol. 2002, 102-103, 315-326. [CrossRef]

18. Koyuncu, I. Reactive dye removal in dye/salt mixtures by nanofiltration membranes containing vinylsulphone dyes: Effects of feed concentration and cross flow velocity. Desalinisation 2002, 143, 243-253. [CrossRef]

19. Dul'neva, T.Y.; Titoruk, G.N.; Kucheruk, D.D.; Goncharuk, V.V. Purification of wastewaters of direct dyes by ultra-and nanofiltration ceramic membranes. J. Water Chem. Technol. 2013, 35, 165-169. [CrossRef]

20. Gomesa, A.C.; Gonçalves, I.C.; de Pinho, M.N. The role of adsorption on nanofiltration of azo dyes. J. Membr. Sci. 2005, 255, 157-165. [CrossRef]

21. Uzal, N.; Yilmaz, L.; Yetis, U. Nanofiltration and reverse osmosis for reuse of indigo dye rinsing waters. Sep. Sci. Technol. 2010, 45, 331-338. [CrossRef]

22. Körbahti, B.K.; Artut, K.; Geçgel, C.; Özer, A. Electrochemical decolorization of textile dyes and removal of metal ions from textile dye and metal ion binary mixtures. Chem. Eng. J. 2011, 173, 677-688. [CrossRef]

23. Cheng, S.; Oatley, D.L.; Williams, P.M.; Wright, C.J. Characterisation and application of a novel positively charged nanofiltration membrane for the treatment of textile industry wastewaters. Water Res. 2012, 46, 33-42. [CrossRef] [PubMed]

24. Chandramowleeswaran, M.; Palanivelu, K. Treatability studies on textile effluent for total dissolved solids reduction using electrodialysis. Desalination 2006, 201, 164-174. [CrossRef]

25. Ho, Y.S.; McKay, G. Sorption of dye from aqueous solution by peat. Chem. Eng. J. 1998, 70, 115-124. [CrossRef]

26. Delval, F.; Crini, G.; Morin, N.; Vebrel, J.; Bertini, S.; Torri, G. The sorption of several types of dye on crosslinked polysaccharides derivatives. Dyes Pigm. 2002, 53, 79-92. [CrossRef]

27. Zhu, M.X.; Li, Y.P.; Xie, M.; Xin, H.Z. Sorption of an anionic dye by uncalcined and calcined layered double hydroxides: A case study. J. Hazard. Mater. 2005, 120, 163-171. [CrossRef] [PubMed]

28. Mon, J.; Flury, M.; Harsh, J.B. Sorption of four triarylmethane dyes in a sandy soil determined by batch and column experiments. Geoderma 2006, 133, 217-224. [CrossRef]

29. Wawrzkiewicz, M. Removal of C.I. Basic Blue 3 dye by sorption onto cation exchange resin, functionalized and non-functionalized polymeric sorbents from aqueous solutions and wastewaters. Chem. Eng. J. 2013, 217, 414-425. [CrossRef]

30. Široký, J.; Blackburn, R.S.; Bechtold, T.; Taylor, J.; White, P. Alkali treatment of cellulose II fibres and effect on dye sorption. Carbohydr. Polym. 2011, 84, 299-307. [CrossRef]

31. Razali, M.; Kim, J.F.; Attfield, M.; Budd, P.M.; Drioli, E.; Lee, Y.M.; Szekely, G. Sustainable wastewater treatment and recycling in membrane manufacturing. Green Chem. 2015, 17, 5196. [CrossRef]

32. Qu, X.; Brame, J.; Li, Q.; Alvarez, P.J.J. Nanotechnology for a safe and sustainable water supply: Enabling integrated water treatment and reuse. Acc. Chem. Res. 2013, 46, 834-843. [CrossRef] [PubMed]

33. Jiménez-Jiménez, J.; Rubio-Alonso, M.; Eliche-Quesada, D.; Rodriguez-Castellón, E.; Jiménez-López, A. Synthesis and characterisation of acid mesoporous phosphate heterostructure (PPH) materials. J. Mater. Chem. 2005, 15, 3466. [CrossRef]

34. Jiménez-Jiménez, J.; Rubio-Alonso, M.; Eliche-Quesada, D.; Castellón, E.R.; Jiménez-López, A. Synthesis and characterization of mixed silica/zirconia and silica/titania porous phospate heterostructures (PPH). J. Phys. Chem. Solids 2006, 67, 1007-1010. [CrossRef]

35. Jiménez-Jiménez, J.; Algarra, M.; Castellón, E.R.; Jiménez-López, A.; Esteves da Silva, J.C.G. Hybrid porous phosphate heterostructures as adsorbents of $\mathrm{Hg}(\mathrm{II})$ and $\mathrm{Ni}(\mathrm{II})$ from industrial sewage. J. Hazard. Mater. 2011, 190, 694-699. [CrossRef] [PubMed]

36. Pierotti, R.A.; Rouquerol, J. Reporting Physisorption Data for Gas/Solid Systems with Special Reference to the Determination of Surface Area and Porosity. Pure Appl. Chem. 1985, 57, 603.

37. Lowell, S. Characterization of Porous Solids and Powders: Surface Area, Pore Size and Density; Springer: Berlin, The Netherlands, 2004. 
38. Moreno-Tost, R.; Oliveira, M.L.; Eliche-Quesada, D.L.; Jiménez-Jiménez, J.; Jiménez-López, A.; Rodríguez-Castellón, E. Evaluation of Cu-PPHs as active catalysts for the SCR process to control NOx emissions from heavy duty diesel vehicles. Chemosphere 2008, 72, 608-615. [CrossRef] [PubMed]

39. Eliche-Quesada, D.; Macias-Ortiz, M.I.; Jiménez-Jiménez, J.; Rodríguez-Castellón, E.; Jiménez-López, A. Catalysts based on $\mathrm{Ru} /$ mesoporous phosphate heterostructures (PPH) for hydrotreating of aromatic hydrocarbons. J. Mol. Catal. A 2006, 255, 41-48. [CrossRef]

40. Soriano, M.D.; Jiménez-Jiménez, J.; Concepción, P.; Jiménez-López, A.; Rodríguez-Castellón, E.; López Nieto, J.M. Selective oxidation of H2S to sulfur over vanadia supported on mesoporous zirconium phosphate heterostructure. Appl. Catal. B Environ. 2009, 92, 271-279. [CrossRef]

41. Freundlich, H.; Heller, W. On Adsorption in Solution. J. Am. Chem. Soc. 1939, 61, 2228. [CrossRef]

42. Sips, R. On the structure of a catalyst surface. J. Chem. Phys. 1948, 16, 490. [CrossRef]

43. Seredych, M.; Rodríguez-Castellón, E.; Biggs, M.J.; Skinner, W.; Bandosz, T.J. Effect of visible light and electrode wetting on the capacitive performance of S- and N-doped nanoporous carbons: Importance of surface chemistry. Carbon 2014, 78, 540-558. [CrossRef]

44. Gupta, V.K.; Gupta, B.; Rastogi, A.; Agarwal, S.; Nayak, A. A comparative investigation on adsorption performances of mesoporous activated carbon prepared from waste rubber tire and activated carbon for a hazardous azo dye-Acid Blue 113. J. Hazard. Mater. 2011, 186, 891-901. [CrossRef] [PubMed]

45. Shirzad-Siboni, M.; Jafari, S.J.; Giahi, O.; Kim, I.; Lee, S.M.; Yang, J.K. Removal of acid blue 113 and reactive black 5 dye from aqueous solutions by activated red mud. J. Ind. Eng. Chem. 2014, 20, 1432-1437. [CrossRef]

46. Schumacher, C.; Seaton, N.A. Modeling of Organically Functionalized Mesoporous Silicas for the Design of Adsorbents. Adsorption 2005, 11, 643-648. [CrossRef]

47. Huang, D.; Sha, Y.; Zheng, S.; Liu, B.; Deng, C. Preparation of phenyl group-functionalized magnetic mesoporous silica microspheres for fast extraction and analysis of acetaldehyde in mainstream cigarette smoke by gas chromatography-mass spectrometry. Talanta 2013, 115, 427-434. [CrossRef] [PubMed]

48. Saad, N.; Al-Mawla, M.; Moubarak, E.; Al-Ghoul, M.; El-Rassy, H. Surface-functionalized silica aerogels and alcogels for methylene blue adsorption. RSC Adv. 2015, 5, 6111. [CrossRef]

49. Saraji, M.; Khaje, N. Phenyl-functionalized silica-coated magnetic nanoparticles for the extraction of chlorobenzenes, and their determination by GC-electron capture detection. J. Sep. Sci. 2013, 36, 1090-1096. [CrossRef] [PubMed] 